\title{
SMOKING AWARENESS AND HABITS AMONG DENTAL STUDENTS AT THE FACULTY OF DENTISTRY, KING ABDULAZIZ UNIVERSITY IN JEDDAH, SAUDI ARABIA... WHAT CAN WE DO TO HELP?
}

\author{
Nadia Al-Hazmi*
}

\begin{abstract}
Background and Objectives: Tobacco epidemic is affecting the whole world. By 2025 the numbers of smokers are expected to increase from 1.1 billion adults to 1.6 billion. Students are a vulnerable and an important target for tobacco industry, despite the fact that Tobacco Use Prevention and Cessation is a competence in their curriculum they must master before graduating.
\end{abstract}

Material and methods: 500 questionnaires were distributed to students attending undergraduate dental school at King Abdulaziz University Faculty of Dentistry (KAUFD). Response rate was 77.2\%. Questionnaire consisted of five parts: general information; questions related to cigarette smoking; questions related to hooka/waterpipe smoking; questions related to shisha smoking and questions for non-smokers. The data was analyzed using the SPSS-PC package. Analysis included simple descriptive statistics in the form of percentages, frequency distributions and bar graphs; a $p$ value less than 0.05 was considered significant.

Results: 368 dental students who answered the questionnaire, $19.2 \%$ students were smokers and $80.8 \%$ (31.1\% males and $68.9 \%$ females) were non-smokers. According to year of study, the highest percentage of students who smoked were in their senior years $\left(5^{\text {th }}: 24.3 \%\right)$. Peer pressure was the most likely reason to start smoking, as well as pressure from the school. There is a clear need for the school to implement more ways to help students cope with the stress of academic load, as well as more awareness of the addictive nature of tobacco use, to empower the students to fight the pressures both within and outside their school life.

KEY WORDS: Awareness; Cigarette; Dental Students; Smoking; Prevalence; Waterpipe; hooka; shisha

* Assistant Professor of Oral Biology, Course Director, Oral Biology, Oral Biology Department, King Abdulaziz University Faculty of Dentistry, Jeddah, Saudi Arabia 


\section{INTRODUCTION}

The tobacco epidemic is a world-wide phenomenon but is increasingly affecting developing countries ${ }^{[1]}$. By 2025, the number of smokers is expected to increase from 1.1 billion adults to 1.6 billion $^{[2-3]}$. Use of tobacco products represents the major cause of preventable illness and death in the developed world, having killed about 100 million people in the 20th century. It is expected to kill 1 billion in the 21 st century ${ }^{[1]}$.

Cigarette smoking causes about 1 out of every 5 deaths in the United States annually ${ }^{[4]}$. Tobacco consumption is also responsible for a great number of diseases. It increases cancer mortality by $28 \%$, as well as causing $36 \%$ of all respiratory-related deaths, and $14 \%$ of all cardiovascular-related deaths. It also causes osteoporosis, stomach and duodenal ulcers, erectile dysfunction and infertility, cataract, and age-related macular degeneration ${ }^{[5-6]}$. Similarly, it causes serious oral diseases and various oral conditions such as oral cancer, cancer recurrence, adult periodontal diseases, congenital defects, leukoplakia, periodontitis, and delayed wound healing ${ }^{[7-12]}$.

Students are a vulnerable and an important target for the tobacco industry. Because tobacco consumption among students is affected by psychological, physical, emotional, and interpersonal relationships, tobacco companies use all available tactics to lure youth down a path of nicotine addiction and eventual death. Studies have show that smoking and smokeless tobacco use start during adolescence ${ }^{[6,13]}$. According to the 2013 CDC report, $88 \%$ of daily adult smokers report they started smoking before the age of 18 years ${ }^{[5]}$.

The rate of smoking among US college students has recently reached 30 percent. The use of multiple tobacco products-such as cigarettes, cigars, and smokeless tobacco has become common among younger people ${ }^{[14]}$. There is also growing evidence that waterpipe/Hookah, also known as hubbly-bubbly, and shisha smoking among youth has dramatically increased worldwide ${ }^{[15-16]}$.

During the last 30 years, the amount of tobacco products imported into the kingdom of Saudi Arabia has increased 40-fold (from 1,061 to 41,440 tons) ${ }^{[17-18]}$. Saudi Arabia spends an average of 600 million Saudi Arabian Riyals (SAR) (approximately 150 million USD) on tobacco annually ${ }^{[19]}$. It ranks fourth in the world in terms of tobacco sales and ranks 23rd among the world's largest consumers of tobacco ${ }^{[20-21]}$.

The aim of our study was to investigate the prevalence of smoking, smoker's behavior and the factors associated with tobacco use among Saudi dental students in the Dental Faculty at king AbdulAziz University.

\section{MATERIAL AND METHODS}

After obtaining ethical approval and permission from Scientific Research Unit in KAUFD the distribution of 500 questionnaires was initiated among dental students from the 2nd year to internship year. The questionnaire were anonymous and voluntary and we ended up with a response rate of $77.2 \%$, where the number of students who responded to the questionnaire were 386 out of 500 students; (166 male students and 220 female students).

The data for this study was collected through self-administered questionnaires and was coded and entered into a database program prior to the final analysis using the SPSS-PC package. Analysis of data included simple descriptive statistics in the form of percentages, frequency distributions and bar graphs; statistical significance was determined by cross tabulation, and the level of significance.

The survey questionnaire was developed in accordance with international guidelines ${ }^{[22]}$, as well 
as instruments that have been used and tested in English. The questionnaire was piloted on 12 dental student ( 6 males and 6 females) from different years of study (2nd year-to-internship year), as a sample of the wider group to assess any needed modifications. Questions were further modified to address issues revealed during the piloting. The questionnaire comprised five modules: General information including: year of study, sex, General Point Average (GPA) attained in the previous year. The smoking module was subdivided into "cigarette smoking; hooka/moassel/waterpipe/hubbly bubbly smoking and finally shisha smokers. The last part was left for those who answered they did not smoke.

\section{Procedure:}

Students were randomly recruited and initially interviewed by two trained Teacher Assistants (TAs) and were then left to complete the questionnaires by by themselves in the classroom under the supervision of the TAs. Forms were then collected from the students and delivered to the author for screening questionnaires and data analysis. To improve the validity of students' responses, no teachers or other dental students were allowed in the classroom during data collection. Verbal and written consent was given by the students after the purpose of the study was explained to them and the reassurance of anonymity and confidentiality of the data at all times during handling and storage.

\section{Statistical Analysis}

The data for this study was collected, coded and entered into a database program prior to the final analysis using the SPSS-PC package. Data was summarized as number and percent of total. Descriptive statistics, and the chi-squared test to analyze the correlation between variables, were used. P-value of less than 0.05 was considered significant. All the tests and results were obtained with a Confidence Interval of $95 \%$.

\section{RESULTS}

Out of a total of 500 students, 114 refused to participate, making the response rate $77.2 \%$ and reducing the total sample size to 386 participants. Males completed 166 questionnaires (43.0\%) and females completed 220 (57.0\%). Results revealed the prevalence of smoking, the behavior of smokers, and the factors that are associated with tobacco use among the dental students.

\section{Prevalence of smoking}

Of the 386 dental students who answered the questionnaire, $19.2 \%$ students stated that they are current smokers while $80.8 \%$ (31.1\% males and $68.9 \%$ females) stated they are not, nor have ever smoked. According to year of study, the highest percentage of students who currently smoke was seen in the $2^{\text {nd }}$ year (also considered year 1 of Dentistry as the $1^{\text {st }}$ year is a General Sciences Year based on which, according to GPA score students can then apply to the medical schools), and the 5 th year $(24.3 \%)$ which is the year before the final year and one that is congested with clinical work (Figure 1). Results showed that students who smoke only cigarette are $11.9 \%$, those who smoke only hookah/waterpipe was only $9.8 \%$ and only $2.8 \%$ revealed they smoke shisha only. Meanwhile, $3.4 \%$ revealed to be smoking both cigarettes and hookah/ waterpipe; $1.3 \%$ cigarette and shisha and 1.8\%/ hookah/waterpipe and shisha (Figure 2).

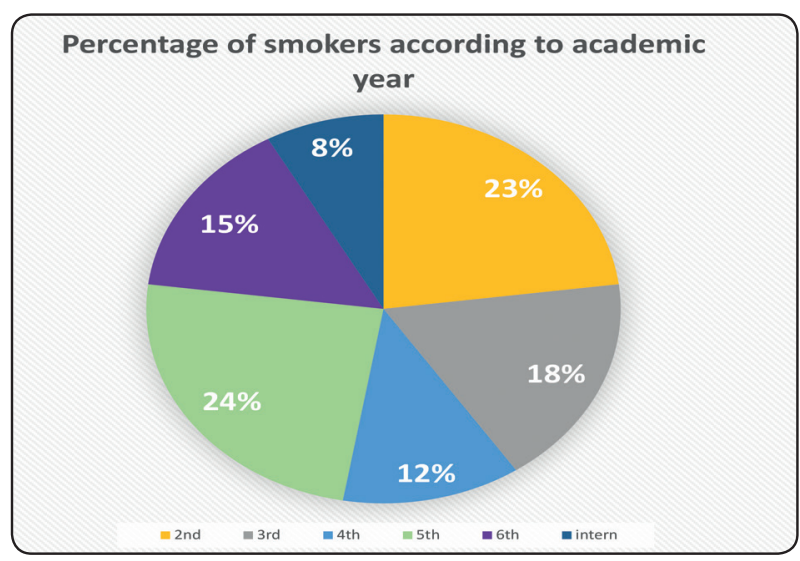

Fig. (1) 


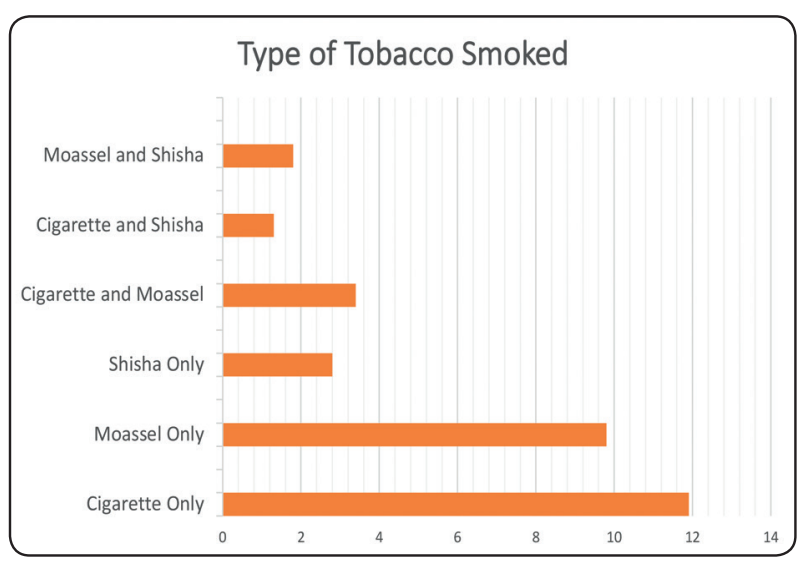

Fig. (2)

\section{Cigarette smoking}

When asked about the trigger that induced them to start smoking, $32.6 \%$ of students answered 'stress', 6.5\% answered 'unhappiness/depression', $39.1 \%$ answered 'need to concentrate'. Other reasons included peer pressure and the need to feel 'older' (Figure 3).

When asked about the convenience of buying cigarette, $41.3 \%$ of students found cigarettes 'expensive' while $34.8 \%$ thought of them as being 'cheap'. In regards to cigarette ban, $41.3 \%$ of students are in favor of banning smoking in all areas while $63 \%$ are in favor of banning smoking only in closed areas.

\section{Hooka/waterpipe smoking}

$42.1 \%$ of students answered that they started smoking hooka/waterpipe because their friends smoke it, $2.6 \%$ because it makes them more feel older, $10.5 \%$ because they were curious towards it, $15.8 \%$ because they felt stressed and it helped them cope with it (Figure 4). When asked about the convenience of hooka/waterpipe, $42.1 \%$ find hooka/waterpipe expensive while $47.4 \%$ found it reasonable. $26.3 \%$ of students are in favor of banning hooka/waterpipe in all areas but $42.1 \%$ believe it should be banned only in closed areas.

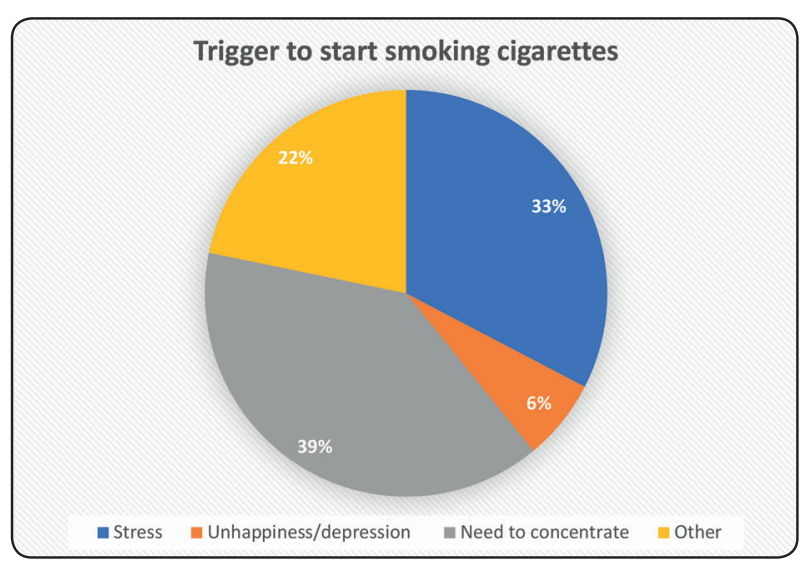

Fig. (3) Reasons given by students when asked 'why did you start smoking cigarettes?'

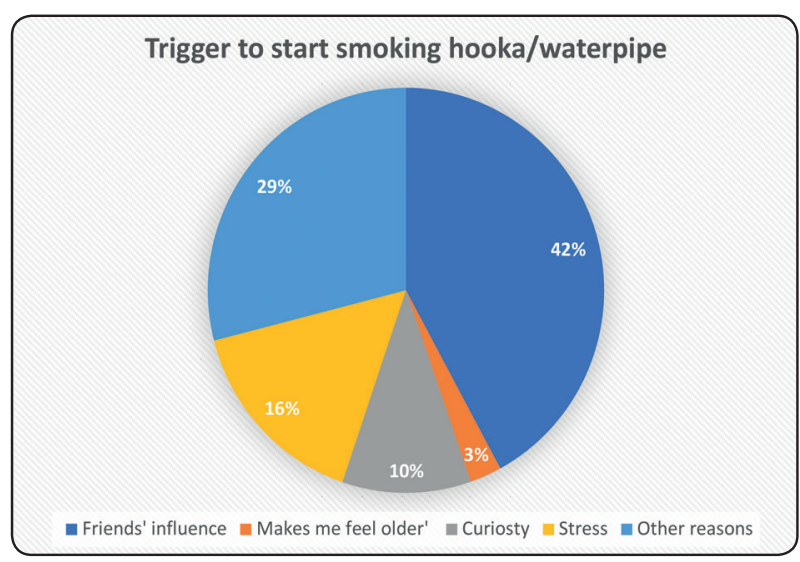

Fig. (4) Reasons given by students when asked 'why did you start smoking hooka/waterpipe?'

\section{Shisha smoking}

In regards to shisha smoking, $18.2 \%$ of students started smoking because their friends also smoked shisha, $9.1 \%$ because shisha smoking makes them feel older, $9.1 \%$ because they want to be seen as 'different', $9.1 \%$ out of curiosity, $9.1 \%$ because they felt stressed and $9.1 \%$ didn't know (Figure 5). $27.3 \%$ of students found shisha 'expensive' and $45.5 \%$ 'cheap'. $27.3 \%$ of students are in favor of banning shisha smoking everywhere while $45.51 \%$ of students think the banning should only be in closed areas. 


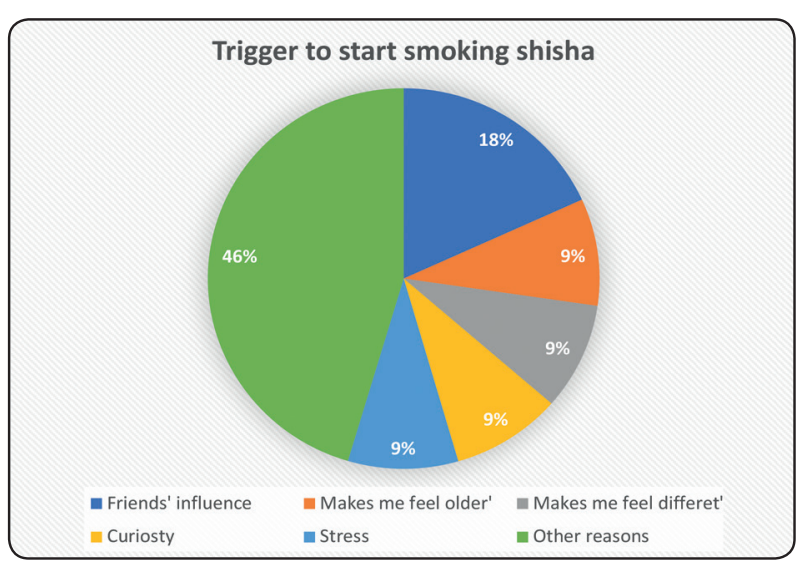

Fig. (5) Reasons given by students when asked 'why did you start smoking shisha?'

When probed on what could make them stop their tobacco habits, among the cigarette, hooka/ waterpipe, and shisha smokers their answers ranged around 'confidence and determination' while fewer described an incentive to stop would be having a 'relaxed and successful lifestyle'.

\section{DISCUSSION}

Tobacco use habits are widespread among dental students. Despite the fact that students are aware of the detrimental effects of tobacco on both general and oral health, they nonetheless pick up the habit and rationalize the reason as peer-pressure or dealing with stress. Furthermore, the religious upbringing of this homogeneously Islamic community plays a role in camouflaging statistics of when students actually pick up the habit. Azhar et. al. showed that smoking was higher among female students not in medical school (4.2\%) as compared to those in medical schools $(0.32 \%)$. This could be because medical students are taught of the harmful effects of smoking and become more aware ${ }^{[23]}$. Many studies have shown that regular smokers start the habit before college; therefore, the later a person is exposed to tobacco, the less likely the habit will be started ${ }^{[5-6,13]}$. This study indicates that smokers were generally encouraged to start smoking to relieve the stress of dental school by looking at their friends who already smoked. It was interesting to see that both cigarette and shisha smoking, which are pure tobacco products, were more related to the student's need to relieve stress, whereas hooka/waterpipe smoking, which has a high percentage of flavors, is more of a social behavior. During one session of hooka/waterpipe smoking that is usually done during social events can results in the inhalation of more toxins than cigarette smoking. In fact, 60 minutes of hookah/waterpipe use results in the inhalation of $90,000 \mathrm{ml}$ of smoke as compared to $500 \mathrm{ml}$ from a cigarette, and 1.7 times more nicotine ${ }^{[24]}$.

Our results show that this view was upheld despite the Tobacco Use Prevention and Cessation (TUPAC) module they take during their $4^{\text {th }}$ year (one of the highest percentage of smokers is seen in the $5^{\text {th }}$ year). This shows that the stress and belief that smoking somehow helps in its relief is a stronger motive to keep the habit than the fear of general and oral diseases as well as the contradiction of practicing TUPAC with their patients while the students themselves smoke. In fact, a common question during the Behavioral and Oral Biology Courses where they are taught to carry out TUPAC intervention has been "But what if we ourselves smoke? Does that make us hypocritical?" This is a clear and optimistic indication that many of these students view the habit as detrimental and strive to be professional and ideal with their patients. The dental school must play a more active role in counseling students who may wish to stop the habit. There was a distinction in our work in highlighting cigarette, hooka/waterpipe and shisha as three separate entities. The reason behind this is cultural since hooka/waterpipe is seen more as a social occurrence and is the most common type of smoked tobacco among women ${ }^{[18]}$. However, cigarettes and shisha are seen as more "fundamental tobacco products" making their addiction somewhat stronger. 


\section{CONCLUSION}

There is a clear need for the dental school to implement more ways to help students cope with the stress of academic load, as well as more awareness of the addictive nature of tobacco use, to empower the students to fight the pressures both within and outside their school life. The best way this could be achieved would be by starting such awareness discussions and debates during the first years of dental school, rather than waiting for the fourth year to discuss the issue in depth.

\section{REFERENCES}

1- World Health Organization (2008) WHO report on the global tobacco epidemic.

2- Bala M, Strzeszynski L, Cahill K (2008) Mass media interventions for smoking cessation in adults. Cochrane Database Syst Rev: CD004704

3- The World Bank: Jha P, Chaloupka FJ (2015) Chapter 2: Cancer: disease control priorities in Curbing the Epidemic: Governments and the Economics of Tobacco Control (Vol. 3, Development in Practice Series). Third edition, Gelband H, Jha P, Sankaranarayanan R, Horton S eds., The International Bank for Reconstruction and Development, Washington, DC. (23-44).

4- Centers for Disease Control and Prevention (2008) Smoking-attributable mortality, years of potential life lost, and productivity losses-United States, 2000-2004. MMWR Morb Mortal Wkly Rep 57: 1226-1228.

5- Action on Smoking and Health (2013) ASH action on smoking and health fact sheets statistics: illness and death introduction, deaths caused by smoking, non-fatal diseases, resources April 2013. Accessed from www.ash.org.uk on mm-dd-yyyy.

6- US Department of Health and Human Services (2004) The health consequences of smoking: a report of the Surgeon General. US Department of Health and Human Services, Washington DC.

7- Gelskey SC (1999) Cigarette smoking and periodontitis: methodology to assess the strength of evidence in support of a causal association. Community Dent Oral Epidemiol 27: 16-24.

8- Little J, Cardy A, Munger RG (2004) Tobacco smoking and oral clefts: a meta-analysis. Bull World Health Organ 82: 213-218.
9- Petersen PE (2003) Tobacco and oral health - the role of the World Health Organization. Oral Health Prev Dent 1: 309-315.

10- Reibel J (2003) Tobacco and oral diseases. Update on the evidence with recommendations. Med Princ Pract 12: 22-32.

11- Tomar SL (2001) Dentistry's role in tobacco control. J Am Dent Assoc 32: 30S-35S.

12- Vanobbergen J, Nuytens P, van Herk M, De Visschere L (2007) Dental students' attitude towards anti-smoking programmes: a study in Flanders, Belgium. Eur J Dent Educ 11: $177-183$.

13- Campaign for Tobacco-Free Kids (2009) The path to smoking addiction starts at very young ages.

14- United States Public Health Service, Office of the Surgeon General (2013) Accessed from www.addiction. surgeongeneral.com on 03-01-2013.

15- Maziak W, Jawad M, Jawad S, Ward KD, Eissenberg T, et al. (2015) Interventions for waterpipe smoking cessation. Cochrane Database Syst Rev: CD005549.

16- Sutfin EL, McCoy TP, Reboussin BA, Wagoner KG, Spangler J, et al. (2011) Prevalence and correlates of waterpipe tobacco smoking by college students in North Carolina. Drug Alcohol Depend 115: 131-136.

17- Siddiqui S, Ogbeide DO (2001) Profile of smoking amongst health staff in a primary care unit at a general hospital in Riyadh, Saudi Arabia. Saudi J 22: 1101-1104.

18- Abdulghani H, Alrowais N, Alhaqwi A, Alrasheedi A, AlZahir M, et al. (2013) Cigarette smoking among female students in five medical and nonmedical colleges. Int J Gen Med 6: 719-727.

19- Bassiony MM (2009) Smoking in Saudi Arabia. Saudi Med J 30: 876-881.

20- AlMoamary MS (2010) Tobacco consummation: Is it still a dilemma?. Ann Thorac Med 5: 193-194.

21- Mobeireek A (2011) Smoking, once again. Ann Thorac Med 6: 421.

22- World Health Organization. (1998). Guidelines for controlling and monitoring the tobacco epidemic. Geneva, Switzerland: WHO.

23- Azhar A, Alsayed N (2011) Prevalence of smoking among female medical students in Saudi Arabia. Asian Pac J Cancer Prev 3: 4245-4248.

24- Cobb C, Ward KD, Maziak W, Shihadeh AL, Eissenberg T (2010) Waterpipe Tobacco Smoking: An Emerging Health Crisis in the United States. Am J Health Behavior 34 (3):275-285 